\title{
As Mensagens Jmplícitas do Texto e o Delineamento Conceitual do Contrassentido
}

\author{
Roberta Maria Garcia BLASQUE* \\ Esther Gomes de OLIVEIRA**
}

\begin{abstract}
* Doutorado (2015) em Estudos da Linguagem pela Universidade Estadual de Londrina (UEL). Pós-doutoranda na UEL. Contato: robertamblasque@gmail.com.

** Doutorado (2000) em Linguística pela Universidade de São Paulo (USP). Professor Associado C da UEL. Contato: ego@uel.br.
\end{abstract}

\begin{abstract}
Resumo:
Neste estudo, cuja fundamentação teórica é a Semântica Argumentativa, pesquisamos os conteúdos implícitos propostos por Oswald Ducrot, os pressupostos e os subentendidos, pois os sentidos e os contrassentidos configuram-se nos ditos e não ditos dos enunciados. Discutimos os conceitos e a atuação dos pressupostos e dos subentendidos, mencionando autores que, também, fundamentam-se nas contribuições de Ducrot. Consideramos a pressuposição um mecanismo inscrito na própria língua, e os movimentos implícitos decorrentes agem, consequentemente, como fortes elementos argumentativos. Esse estudo intermediou um contato com as mensagens implícitas do texto, contribuindo para a ancoragem do contrassentido à Semântica Argumentativa e, consequentemente, seu delineamento conceitual, como um conteúdo não linear à extensão do texto, cujo exame demonstra, de modo velado, uma ideia diferente do sentido anteriormente atrelado ao enunciado. Ilustramos os movimentos dos sentidos e dos contrassentidos por meio de peças publicitárias que divulgam cosméticos rejuvenescedores, a fim de mostrar posturas diferentes - ocultar a idade (propaganda) e aceitar a idade (Gerontologia) - que proporcionam uma base sólida ao surgimento do contrassentido como fenômeno semântico. Constatamos a complementaridade entre sentidos e contrassentidos, os quais funcionam como estratégia argumentativa implícita e transmitem efeitos de sentido.
\end{abstract}

\section{Palavras-chave:}

Semântica Argumentativa. Mensagens implícitas. Contrassentido.

Signum: Estudos da Linguagem, Londrina, v. 23, n. 2, p. 114-129, ago. 2020

Recebido em: $29 / 05 / 2020$

Aceito em: 30/07/2020 


\section{As Mensagens Implícitas do Texto e o Delineamento Conceitual do Contrassentido}

Roberta Maria Garcia Blasque; Esther Gomes de Oliveira

A argumentação se sustenta tanto pelo que dizcom todas as letras quanto por aquilo que leva a entender

(AMOSSY, 2018, p. 178).

\section{INTRODUÇÃo}

Segundo a Gerontologia, o idoso deve, necessariamente, aceitar as suas limitações e a sua idade cronológica, sem desejos de retorno a fases anteriores do ciclo de vida, para alcançar uma velhice ativa e próspera. Assumindo uma concepção diferenciada, a mídia divulga propagandas de cosméticos rejuvenescedores e, em seu discurso, transmite sentimentos de medo e aversão em relação à velhice. Nesse contexto, encontramos posturas ideológicas diferentes: a aceitação da idade (Gerontologia) e a ocultação da idade (publicidade), subsidiando o surgimento do contrassentido, ou seja, essas peças publicitárias passaram a funcionar, de acordo com essa constatação, como contrassentidos do discurso gerontológico e vice-versa.

Desse modo, atrelamos o contrassentido à Semântica Argumentativa, associando-o às informações implícitas do texto. Além de configurar-se nos anúncios como um todo, verificamos que o contrassentido estava presente dentro de sua constituição, ou seja, sentidos e contrassentidos estruturavam, argumentativamente, o texto publicitário. A partir disso, acrescentamos à nossa pesquisa a noção de interação e complementaridade, tendo em vista que as diferenças ideológicas entre publicidade e Gerontologia são dialogantes e, juntas, constroem a persuasão do anúncio, transmitindo efeitos de sentido e determinados valores.

Nosso objetivo é apresentar e divulgar o delineamento conceitual do contrassentido como um fenômeno semântico implícito, mostrando que, em diversos corpus de pesquisa, há a possibilidade de o contrassentido manifestar-se como estratégia argumentativa implícita e transmitir efeitos de sentido, basta existir uma ideia diferente do sentido anteriormente atrelado ao enunciado. Consequentemente, será perceptível a interação ideológica situada nas informações implícitas do texto, por meio de sentidos, contrassentidos e estratégias argumentativas. O contraste, proveniente do contrassentido, proporciona uma análise argumentativa e de atribuição de significados, com expressivas contribuições para o conhecimento das possibilidades da linguagem.

A nossa pesquisa correlaciona o contrassentido à Semântica Argumentativa, demonstrando-o no discurso publicitário para idosos. No entanto, esse fenômeno, como mencionado anteriormente, pode surgir em variados corpus, sendo fonte ilimitada de estudo. Neste artigo, não apresentaremos análises mais pontuais de peças publicitárias, pois nossa intenção é expor o conceito de contrassentido, mostrando sua ancoragem à Semântica Argumentativa, apenas informar que ele foi descoberto a partir das divergências ideológicas entre Gerontologia e publicidade. Desse modo, pesquisamos os conteúdos implícitos propostos por Oswald Ducrot, os pressupostos e os subentendidos, pois os sentidos e os contrassentidos configuram-se nos ditos e não ditos dos enunciados. Discutimos os conceitos e a atuação dos pressupostos e dos subentendidos, mencionando autores que, também, fundamentam-se nas contribuições de Ducrot. 


\section{Semântica Argumentativa}

No fim da década de setenta e início dos anos oitenta, um dos objetivos principais dos estudos da linguagem, devido à Linguística da Enunciação, era a argumentação. Para Oliveira (2004, p. 122), “os mecanismos que interagem dentro da realidade discursiva, levando-se em conta os aspectos cognitivos e informativos da linguagem, propiciam um campo de pesquisa vastíssimo, sendo responsáveis por uma multiplicidade de teorias argumentativas". Assim, o percurso das pesquisas argumentativas, desde a Antiguidade até o século XX, favoreceu o surgimento de uma nova teoria semântica, preocupada com a análise do enunciado, proporcionando outro enfoque aos estudos da significação.

A Semântica Argumentativa surgiu na França, em 1976, com a publicação, na revista Langages, do artigo intitulado "L'argumentation dans la langue", de Jean-Claude Anscombre e Oswald Ducrot (1976), e tem como base a teoria de que a argumentação está inscrita na própria língua. $\mathrm{O}$ artigo apresenta essa nova teoria semântica, considerada uma das vertentes da Pragmática, enquanto estudo das relações entre os interlocutores numa situação de discurso. Segundo Guimarães (1997, p. 147-148), a ideia fundamental de Ducrot mostra que o valor argumentativo de uma frase não está apenas na consequência das informações lançadas, mas também nos efeitos persuasivos concretizados por determinadas expressões, servindo para dar uma orientação argumentativa ao enunciado e conduzir o destinatário a direções específicas.

Conforme Barbisan (2013, p. 20), "Do ponto de vista semântico, a Teoria da Argumentação na Língua postula que a palavra contém, na língua, uma significação que permite certas continuações no enunciado e impede outras". Não basta apenas uma entrega de informação/conteúdo, ou seja, o enunciado não é definido nele mesmo, pois, quando um locutor produz um discurso, lançando algo em que acredita, ele espera uma resposta, uma reação. O sentido do enunciado está na interação que se estabelece entre os indivíduos, no ato da comunicação, em nível argumentativo, orientando o outro a determinada conclusão. Para a autora, "a argumentação torna-se fundamental na linguagem. Está inscrita na língua, é inerente a ela, está na própria natureza da língua. Essa é a razão pela qual a Semântica Argumentativa é também denominada Teoria da Argumentação na Língua" (p. 21).

Para Ducrot (1977), as relações intersubjetivas inerentes à fala não se reduzem à comunicação, ou seja, não ocorre apenas a troca de conhecimentos, mas, ao contrário, existe uma grande variedade de relações inter-humanas, para as quais a língua oferece não apenas a ocasião e o meio, mas também um quadro institucional dotado de regras. Dessa forma, "A língua, então, não é mais apenas o lugar onde os indivíduos se encontram; ela impõe também, a esse encontro, formas bem determinadas [...]. Ela perde sua inocência” (p. 12). Devemos, segundo o autor, considerar a língua como um jogo, ou melhor, como o estabelecimento das regras de um jogo, e não somente como um instrumento de comunicação. Oliveira (1999) destaca: "A língua, na teoria semântica de Ducrot, não serve apenas para a função comunicativa, mas exerce o papel de revelar, de transmitir o pensamento" (p. 55).

A linguagem é uma forma de ação essencialmente dialógica e um instrumento social que se propõe a atuar no comportamento do outro, levando os falantes a partilhar seus juízos. Dessa forma, a Semântica Argumentativa, baseada na relação locutor - alocutário, definindo a perspectiva dialógica, sustenta o jogo de relações intersubjetivas travado entre interlocutores no uso da linguagem. E, segundo Barbisan (2013, p. 23),

o exercício da linguagem se dá entre dois seres de fala: o locutor e o alocutário. Ao se enunciar, falando ou escrevendo, o locutor produz combinações próprias, dentre aquelas que a frase permite. Ou seja, o locutor argumenta sobre a realidade ao estabelecer continuações, o que indica, mais uma vez, que o sentido assim produzido não é representativo da realidade. É o locutor, ao escolher combinações linguísticas, que atribui sentidos à realidade. É o seu 'olhar' sobre a realidade. Esse sentido, entendido desse modo, espera uma continuação, uma resposta do alocutário. Temos, assim, mais uma vez, a alteridade de Platão, tão bem compreendida por Saussure, vista agora no nível dos enunciados. 
Koch (1984) prossegue nos postulados de Ducrot ao afirmar que o ato de argumentar, de orientar o discurso no sentido de determinadas conclusões, constitui o ato linguístico fundamental, pois a troca comunicativa entre os indivíduos caracteriza-se pela intencionalidade e pelas escolhas constantes de palavras ou de outras estratégias que, ao transmitirem efeitos de sentido propositais, influenciam no desempenho do outro. Assim, para a pesquisadora, "A neutralidade é apenas um mito: o discurso que se pretende 'neutro', ingênuo, contém também uma ideologia - a da sua própria objetividade” (p. 17).

Ao adotar a argumentação como um fator constitutivo da estrutura de todo e qualquer discurso, e veiculador de ideologia, a Semântica Argumentativa pode preencher o espaço deixado pelas gramáticas de texto, de modo que se deve considerar a orientação argumentativa dos enunciados de um texto como fator de coesão e, principalmente, de coerência textual.

Para Koch (1984), a macrossintaxe do discurso constitui o objeto da Semântica Argumentativa, e é nesse nível, e não na superfície do texto, que se encontra uma série de marcas persuasivas carregadas de ideologia. Dentre as marcas linguísticas da argumentação, Koch destaca as seguintes: as pressuposições; as marcas das intenções, explícitas ou veladas; os modalizadores, que revelam uma atitude perante o enunciado produzido; os operadores argumentativos, responsáveis pelo encadeamento dos enunciados; e as imagens recíprocas, que se estabelecem entre os interlocutores e as máscaras por eles assumidas no jogo de representações (p. 33).

Conforme Barbisan (2013), a busca da explicação do sentido, no uso da língua, por meio da Semântica Argumentativa, teve, inicialmente, duas formas. A primeira, a forma standard, inicial; a segunda acrescentou a noção de polifonia à primeira; e a última, desenvolvida atualmente por Oswald Ducrot e Marion Carel, é denominada de Teoria dos Blocos Semânticos, em que dois discursos evocados por uma entidade linguística e articulados por um conector, portanto ou no entanto, são denominados encadeamentos argumentativos. Por fim, enfatizamos os princípios essenciais da Semântica Argumentativa - a argumentação se inscreve no interior da própria língua; a comunicação tem função interacional e intencional; a linguagem é construída por meio de artifícios argumentativos que direcionam o outro para fins específicos - para, dessa forma, analisarmos as informações implícitas do texto (o dito e o não dito) e chegar à adesão do contrassentido à Semântica Argumentativa.

\section{O Dito e o Não Dito / Pressuposto e Subentendido}

Muitas vezes, um enunciado, na língua falada ou na escrita, permite interpretações que ultrapassam a sequência de marcas presentes na superfície do texto, ou seja, há informações além do que está explicitamente dito pelos sinais aparentes. O enunciado "faz calor" pode significar apenas "faz calor", porém, em determinados cenários, essa afirmação comporta outros significados, como: "abra a janela”, "desligue o aquecedor”, "posso tirar o casaco?", "não tenho nada mais interessante para dizer". Assim, a maior parte dos enunciados tem, além do seu conteúdo explícito, um ou mais conteúdos implícitos, que não são previstos com base apenas no sentido literal, pois eles extrapolam o dito.

Para compreender os sentidos possíveis em uma língua, precisamos, também, desvendar as mensagens implícitas e examinar os motivos da permanência de certos não ditos nas entrelinhas do discurso. Segundo Ilari (2001, p. 92),

Importantíssimos para a interpretação final da mensagem, esses implícitos só podem ser descobertos por um trabalho de conjectura feito a partir de uma avaliação global da situação comunicativa, em que o ouvinte procura recuperar as intenções do falante. Mensagens que comportam esse tipo de implícito são sempre interpretadas como 'indiretas' e obrigam, tipicamente, o ouvinte a perguntar: 'O que foi que ele quis me dizer com isso?', 'Aonde ele quis chegar?' etc. 
Desse modo, para realizar uma leitura eficiente, o leitor deve atentar-se aos sentidos explícitos e implícitos do texto, pois, se não for perspicaz, deixará de priorizar, ou não atingirá, significados essenciais. $O$ cálculo dos implícitos é um procedimento problemático, levando, muitas vezes, a resultados errôneos: a informação implícita não é percebida ou não é devidamente interpretada, causando mal-entendidos. Para exemplificar, de modo simples, o funcionamento dos implícitos, a frase "O tempo continua chuvoso" comunica, de maneira explícita, que o tempo é de chuva no momento da fala, mas, ao mesmo tempo, o verbo "continuar" deixa perceber a informação implícita de que antes o tempo já estava chuvoso.

Além desse exemplo, encontramos, em nosso cotidiano, enunciados mais complexos, principalmente no âmbito político ou publicitário, que, sem as devidas interpretações dos implícitos, podem gerar consequências negativas e prejudicar a imagem pública de uma pessoa ou a eficácia de um produto. Por outro lado, alguns tipos de texto exploram, com malícia ou intenções falaciosas, os conteúdos implícitos, utilizando-os propositalmente, como uma estratégia, em benefício de seus próprios objetivos. Conforme Ferrarezi Junior (2008, p. 176), "a propaganda é um ambiente muito propício para passar mensagens implícitas. Lê-se uma propaganda e logo a gente vai se sentindo obrigado a comprar as coisas".

E, segundo Ilari (2001, p. 84),

as informações veiculadas pelas mensagens lingüísticas apresentam graus diferentes de explicitude. Podem ser consideradas implícitas todas as informações que uma sentença veicula, sem que o falante se comprometa explicitamente com sua verdade. Essas informações precisam então ser 'inferidas' a partir da sentença por meio de algum raciocínio que parte da própria sentença.

As formas implícitas são geralmente utilizadas em momentos nos quais não convém dizer tudo abertamente, quando precisamos dizer e, ao mesmo tempo, agir como se não tivéssemos dito, recusando a responsabilidade de algum comentário. Cabral (2011) cita algumas razões que justificam o emprego de formas implícitas: a existência de um impedimento em relação à determinada informação, o medo de ofender o interlocutor ou de gerar um constrangimento, a alusão a um assunto restrito dentro da comunidade de que participamos, entre outros motivos. Para a autora, conseguimos evitar um confronto se utilizarmos formas de dizer que não exponham o conteúdo dito à contestação, deixando, nessas situações, algum posicionamento implícito. Com isso, "as formas implícitas cumprem a função de dizer o que desejamos dizer sem que sejamos obrigados a assumir que dissemos" (p. 60).

Para Guimarães (2009, p. 62), o uso do implícito proporciona uma sugestão ou acusação, sem envolver, diretamente, o enunciador da mensagem. Assim, "recorre-se aos implícitos para que se possam construir os sentidos possíveis do não dito, do interdito, do subtexto, da subjetividade". Os diversos sentidos do enunciado, presentes nos implícitos, subordinam-se ao contexto no qual o enunciado é produzido e à intenção com a qual foi formulado. Muitas vezes, a percepção de implícitos depende do contexto sociossituacional, do conhecimento mútuo entre os interlocutores, de seus saberes partilhados e de suas relações.

Segundo Charaudeau e Maingueneau (2004), a literatura semântica e pragmática menciona uma variedade de conteúdos implícitos, como inferências, implicações e implicaturas, alusões e insinuações, ironia, entre outros. Das distinções mais relevantes, os autores citam a que foi estabelecida por Oswald Ducrot, entre pressuposto e subentendido, dois tipos de conteúdos implícitos que se opõem ao conteúdo explícito, ou posto. Além disso, algumas mensagens implícitas são marcadas, possuindo, no enunciado, um suporte lexical ou morfossintático, enquanto outras não são, ou são menos claramente.

Os conteúdos implícitos que não apresentam marca explícita no enunciado, caso mais frequente, podem ser identificados com base em outros fatores, em princípios contextuais, como determinado saber enciclopédico. Desse modo, "O trabalho interpretativo consiste, pois, em combinar as informações extraídas do enunciado com certos dados contextuais, [...], para construir uma representação semântico-pragmática coerente e verossímil do enunciado" (CHARAUDEAU; MAINGUENEAU, 2004, p. 271). 
Para Cabral (2011), os procedimentos de implícitos separam-se em duas categorias: os discursivos e os não discursivos. Os discursivos dependem do contexto de enunciação e de um raciocínio do interlocutor para serem reconstruídos, e são formados pelos subentendidos. Os procedimentos não discursivos estão inscritos na significação dos elementos que compõem os enunciados, e são constituídos pelos pressupostos. Assim, o subentendido não está inscrito no enunciado, pois ele depende de um raciocínio do interlocutor em torno do enunciado e, muitas vezes, dizemos uma coisa para fazer entender outra. O pressuposto, ao contrário, não depende apenas do raciocínio do interlocutor, uma vez que ele está inscrito na língua, no significado das frases que compõem o enunciado em que se encontra. Um enunciado que contém um pressuposto sempre compreende um conteúdo posto e outro pressuposto. Verificamos o exemplo proposto por Cabral (p. 63):

- enunciado: Paulo parou de fumar;

- posto: Paulo não fuma;

- pressuposto: Paulo fumava antes;

- subentendido: a afirmação pode atuar como uma advertência a um interlocutor que fuma muito e tem Paulo como um exemplo a seguir.

Conforme a autora, a expressão verbal "parar de" mais o verbo "fumar" põe a negação do ato de Paulo de fumar e pressupõe a prática dessa conduta anteriormente ao momento da enunciação. Além disso, se dissermos "Paulo parou de fumar" a um indivíduo que fuma muito e tem Paulo como exemplo, ele pode entender a afirmação como uma mensagem indireta, pautada na ideia de que ele também deveria parar de fumar. Essa mensagem é deixada apenas no subentendido e o interlocutor pode ou não entender o aviso como uma advertência.

Maingueneau (1996) explica que os interlocutores conseguem captar uma grande parcela dos subentendidos, apoiando-se na situação de enunciação, porém o pressuposto, outro grande tipo de conteúdo implícito, inscreve-se na estrutura do enunciado, independentemente de seus contextos de emprego. O autor apresenta o seguinte exemplo:

- A: estou procurando alguém para consertar meu carro;

- B: meu irmão está em casa;

- A: mas ele está sempre tão ocupado!

Com base na réplica de $\mathrm{B}$, deduzimos o pressuposto "B tem um irmão", configurando-se em uma informação implícita inscrita no próprio enunciado. Além disso, podemos extrair da réplica de $\mathrm{B}$ outro conteúdo implícito: B propõe a A a possibilidade de seu irmão consertar o carro. No entanto, esse sentido não é inferido por A a partir do valor literal da réplica, não está inscrito no enunciado, mas por uma espécie de raciocínio, caracterizando o subentendido. Colocando-se na posição de A, verificamos a seguinte sequência de pensamento: B me diz que seu irmão está em casa; posso presumir que ele fala de modo adequado e, portanto, sua enunciação relaciona-se com o que acabo de dizer; certamente, B pretende me dizer, com isso, que seu irmão conseguiria fazer esse conserto.

Segundo Maingueneau (1996), a existência do subentendido é sempre incerta e a do pressuposto é sempre estável. Desse modo, "qualquer locutor que sabe o português pode, em princípio, identificar os pressupostos, enquanto a decifração dos subentendidos é mais aleatória. Ademais, o número desses subentendidos é aberto por definição" (p. 93). A construção das inferências é um trabalho árduo e complexo, pois, ao lado dos pressupostos, existem setores muito mais instáveis, os subentendidos, determinando tanto os sentidos mais garantidos quanto os mais incertos. Em outra obra (MAINGUENEAU, 2001), o autor retoma essa versatilidade do subentendido e afirma que "na comunicação lingüística, acontece freqüentemente de não sabermos se o enunciado deve ser tomado ou não ao pé da letra, se ele é irônico ou se é uma brincadeira" (p. 22). 
Além disso, o tratamento do implícito é ambíguo, pois se verifica nele tanto uma recusa da franqueza quanto uma marca de delicadeza, tanto uma falta de vontade de convívio quanto uma extrema vontade de convívio. Inclusive, se o implícito for utilizado sem habilidade, pode ser até mais ofensivo do que a sinceridade explícita. Para Maingueneau (1996, p. 95), "Como o implícito se define como um jogo entre o dito e o não dito, um jogo na fronteira, é normal que passe sem cessar de um lado para o outro”.

Sobre os pressupostos, Maingueneau (1996) define-os como uma inferência inscrita no próprio enunciado, independentemente da variedade de seus eventuais contextos enunciativos. A partir disso, o autor propõe uma distinção entre dois níveis de conteúdo de um enunciado: um nível de primeiro plano, correspondente ao que se refere o enunciado - o posto; e um nível no plano de fundo, sobre o qual se apoia o posto - o pressuposto. Corroborando a explicação de Maingueneau, Fiorin (2014) afirma que "o conteúdo explícito será denominado 'posto', enquanto o conteúdo implícito desencadeado pela formulação do enunciado, independentemente da situação de enunciação, será cognominado 'pressuposto"' (p. 23).

Em se tratando da sua relação com a textualidade, o pressuposto desempenha papel fundamental na construção da coerência textual, pois, para progredir, um texto baseia-se em uma informação colocada que converte, depois, em pressuposto. Sem essa informação, haveria apenas uma série de enunciados sem vínculos ou a repetição indefinida do mesmo fato. Por isso, os pressupostos são construídos anteriormente ao enunciado (MAINGUENEAU, 1996).

De acordo com Charaudeau e Maingueneau (2004), os pressupostos (evidências partilhadas) constituem um tipo de base sobre a qual se formulam os postos (informações novas), garantindo a coesão do discurso, quando os postos se encarregam de sua progressão. E, para Maingueneau (1996), classicamente, há dois tipos de pressuposto, os locais e os globais. Os primeiros consistem em uma inclusão, por exemplo, "Quando chegou?" pressupõe "chegou a um determinado momento". Os segundos fundamentam-se em uma antecedência, por exemplo, "Paulo não está mais aqui" pressupõe "Paulo estava aqui anteriormente" e "existe um indivíduo chamado Paulo", cujo destinatário, supostamente, é capaz de identificar. O pressuposto local necessita de uma interrogação parcial (Quem? Onde? Quando?), que diz respeito aos constituintes da frase, e o global faz intervir negação ou interrogação total, que se referem ao conjunto da frase.

Comparando os conteúdos implícitos, Maingueneau (1996, p. 105) afirma:

Pressupostos e subentendidos permitem que os locutores digam sem dizer, adiantem um conteúdo sem assumir completamente sua responsabilidade. No caso do pressuposto, existe um recuamento desse conteúdo; no do subentendido, trata-se antes de uma espécie de adivinhação colocada ao co-enunciador. Ele deve derivar de proposições baseando-se nos princípios gerais que regem a utilização da linguagem. Esses subentendidos não são, portanto, passíveis de predição fora de contexto; de acordo com os contextos, a mesma frase poderá liberar subentendidos totalmente diferentes.

A respeito dessa ausência de responsabilidade pelo dito, Fiorin (2014) acrescenta que, no caso do subentendido, o enunciador consegue esconder-se atrás do sentido literal da frase, para negar a sua real mensagem. Ele não se compromete e, se precisar, pode contestar que tenha dito o que o ouvinte depreendeu de suas palavras, como uma forma de autoproteção. O subentendido não diz, apenas sugere, funcionando como insinuações não marcadas na superfície do texto, ou seja, não são codificados nos componentes lexicais e sintáticos.

O pressuposto é uma informação indiscutível, de responsabilidade do enunciador, e o subentendido é de responsabilidade do enunciatário, cuja informação deve ser atualizada de acordo com a situação comunicativa. O pressuposto designa o que pode ser implicado logicamente pelo posto, não está presente na mensagem de modo explícito, mas está inscrito no enunciado. Já o subentendido é dependente do contexto e ligado à enunciação, alguns itens, como um gesto, um piscar de olhos, uma hesitação, são necessários para o seu aprisionamento. 
Para entendermos esse processo de descomprometimento que ocorre com a manipulação dos subentendidos, verificamos um exemplo de Fiorin (2014): a adversária de certo candidato a um cargo político veiculou uma publicidade em que um locutor perguntava "você sabe mesmo quem é esse candidato?", "sabe de onde ele veio?", "qual a história do seu partido?". Em seguida, aparecia a foto do candidato e o locutor perguntava "sabe se ele é casado?”, “tem filhos?”. Nesse caso, o subentendido estava na opção sexual do candidato, pois a adversária insinuava que ele era homossexual, mesmo sem dizer esse conteúdo explicitamente. Assim, a responsabilidade dessa informação recai na interpretação do público.

Segundo Ducrot (1987), o objeto real de estudo de um semanticista são as diversas ocorrências de um enunciado em diferentes situações, pois a descrição semântica se constitui de um conjunto extremamente heterogêneo. Desse modo, além dos conhecimentos linguísticos, devemos considerar certo número de códigos de ordem psicológica, lógica e sociológica, ou seja, informações referentes às diversas utilizações da linguagem em uma comunidade. Priorizando os diferentes contextos em que um mesmo enunciado é dito, descobrimos vários sentidos. Sob essa perspectiva, Ducrot defende uma semântica que vai além do enunciado, ultrapassando uma descrição semântica apenas linguística e baseando-se no fato de uma frase qualquer poder veicular infinitas significações.

Para dar conta da infinidade de significações decorrentes de variados contextos possíveis, Ducrot (1987) fragmenta a descrição semântica de um enunciado em dois compartimentos principais:

- componente linguístico - atribui a cada enunciado uma significação exclusivamente linguística, sem considerar o contexto. Por exemplo, à A corresponde a significação A';

- componente retórico - produz o sentido do enunciado diante das circunstâncias contextuais. Por exemplo, caberia a esse segundo componente, considerando a significação A' ligada à $\mathrm{A}$ e às circunstâncias X nas quais A é produzido, prever a significação efetiva de A na situação X.

Em busca de melhor compreensão dos componentes anteriores, o autor distingue dois tipos de efeitos de sentido, o pressuposto e o subentendido, descrevendo um deles a partir do componente linguístico, enquanto o outro exige a intervenção do componente retórico. Conforme Ducrot (1987), um dos primeiros critérios que permitem diferenciar pressupostos de subentendidos deriva do comportamento muito particular assumido pelos pressupostos de manterem-se afirmados mesmo sendo submetidos a modificações sintáticas, como a negação, a interrogação e a subordinação.

Por exemplo, se o enunciado "João fumava antigamente" for modificado para "será que João continua fumando?" (interrogação) ou "João não continua fumando" (negação) ou "João continua fumando, ainda que o médico the tenha proibido o cigarro" (subordinação), a sua informação central, "João era fumante", será mantida. Esse comportamento particular frente à negação, à interrogação e à subordinação caracteriza os pressupostos, cujas marcas estão inscritas no enunciado. A tendência do pressuposto é a de sempre resistir às alterações sintáticas, pois, mesmo modificados, trazem mensagens sempre afirmadas. A pressuposição é uma relação de sentido em que, quando alguém diz "X", assume "Y”, e, quando alguém diz "não X", continua assumindo "Y" da mesma forma. No entanto, os testes de mudanças sintáticas não funcionam no caso dos subentendidos.

A partir desses exemplos, Ducrot (1987) verifica uma distinção entre o nível do enunciado, em que o posto e o pressuposto correspondem ao componente linguístico (trata do próprio enunciado, sem considerar suas condições de ocorrência), e o subentendido (ausente do enunciado, considera as condições de ocorrência, o contexto), ao componente retórico. Para o autor,

o fenômeno de pressuposição parece estar em estreita relação com as estruturas sintáticas gerais - o que fornece uma primeira razão para tratá-lo no componente lingüístico onde, evidentemente, deveria ser descrito o valor semântico dessas construções. O mesmo argumento não pode ser empregado, tratando-se dos 
subentendidos, pois a relação com a sintaxe é bem mais difícil de aparecer. [...] existe sempre para um enunciado com subentendidos, um 'sentido literal' do qual tais subentendidos estão excluídos. Eles parecem ter sido acrescentados (p. 19).

Com base em Ducrot, elaboramos o Quadro 1, a seguir, para melhor visualização das noções que abrangem o posto, o pressuposto e o subentendido:

Quadro 1 - O posto, o pressuposto e o subentendido na experiência da comunicação

\begin{tabular}{|c|c|c|c|}
\hline & Posto & Pressuposto & Subentendido \\
\hline Enquanto locutor & $\begin{array}{l}\text { É o que afirmo. Apresentado } \\
\text { como uma evidência, como uma } \\
\text { afirmação incontestável no } \\
\text { interior do qual a conversação } \\
\text { deve se inscrever. }\end{array}$ & $\begin{array}{c}\text { É o que apresento como } \\
\text { pertencendo ao domínio comum } \\
\text { das duas personagens do diálogo, } \\
\text { como o objeto de uma } \\
\text { cumplicidade fundamental que } \\
\text { liga entre si os participantes do } \\
\text { ato de comunicação. }\end{array}$ & $\begin{array}{l}\text { É o que deixo meu ouvinte } \\
\text { concluir, com base nas } \\
\text { circunstâncias da enunciação. }\end{array}$ \\
\hline \multirow[b]{2}{*}{$\begin{array}{c}\text { Em relação ao sistema } \\
\text { de pronomes }\end{array}$} & Posto & Pressuposto & Subentendido \\
\hline & É reivindicado pelo “eu”. & $\begin{array}{l}\text { É apresentado como pertencente } \\
\text { ao "nós", englobando destinador } \\
\text { e destinatário. }\end{array}$ & $\begin{array}{l}\text { É repassado ao "tu", nas } \\
\text { conclusões que ele extrai do } \\
\text { enunciado por sua conta e risco. }\end{array}$ \\
\hline \multirow[b]{2}{*}{$\begin{array}{c}\text { De acordo com imagens } \\
\text { temporais }\end{array}$} & Posto & Pressuposto & Subentendido \\
\hline & $\begin{array}{l}\text { Apresenta-se simultaneamente ao } \\
\text { ato da comunicação, como se } \\
\text { tivesse surgido pela primeira vez, } \\
\text { no universo do discurso, no } \\
\text { momento da realização desse ato. }\end{array}$ & $\begin{array}{l}\text { Mesmo que nunca tenha sido } \\
\text { introduzido anteriormente ao ato } \\
\text { de enunciação, ele procura se } \\
\text { situar em um passado do } \\
\text { conhecimento ao qual o locutor } \\
\text { parece referir-se. }\end{array}$ & $\begin{array}{l}\text { Ocorre em momento posterior a } \\
\text { esse ato, como se tivesse sido } \\
\text { acrescentado por meio da } \\
\text { interpretação do ouvinte. }\end{array}$ \\
\hline
\end{tabular}

Fonte: Elaborado pelas autoras, com base em Ducrot (1987, p. 20-21).

Desse modo, o posto e o pressuposto apresentam-se como contribuições inscritas na língua (não estão ligados a uma reflexão individual dos falantes), como se tivessem sido escolhidos concomitantemente, e aplicam, em seguida, a responsabilidade ao locutor, mesmo que, no caso do pressuposto, o locutor tente partilhar essa responsabilidade com o ouvinte, disfarçando o que diz sob a aparência de uma crença comum (DUCROT, 1987). No caso do subentendido, o ouvinte deve descobri-lo por meio de um procedimento discursivo, de uma espécie de raciocínio, refutando o sentido literal, baseando-se tanto sobre a enunciação quanto sobre o conteúdo dito. Conforme Ducrot, "o enunciado é utilizado em um momento determinado em circunstâncias específicas. O raciocínio do ouvinte poderia então explicitar-se por uma fórmula tipo: se alguém julga que é adequado dizer-me isso é, sem dúvida, porque pensa aquilo” (p. 22).

Ducrot não considera as distinções entre pressuposto e subentendido como conceitos opostos, apenas verifica que as noções desses conteúdos implícitos não estão situadas no mesmo nível. Para ele, "a pressuposição é parte integrante do sentido dos enunciados. O subentendido, por sua vez, diz respeito à maneira pela qual esse sentido deve ser decifrado pelo destinatário" (p. 41). O locutor apresenta sua fala como um enigma para o destinatário resolver. Assim, "É esse processo que ilustra o subentendido: para dizer alguma coisa, faz-se o outro dizer o que se disse" (p. 43).

Segundo Koch (1984), o ponto comum entre ambos refere-se à possibilidade dada, nos dois casos, ao locutor de se retratar; isso é possível, mesmo na pressuposição, porque a informação pressuposta é colocada à margem do discurso, de modo que o locutor não pode ser atacado a seu propósito, já que o discurso posterior, o diálogo esperado e oferecido pelo enunciado portador do pressuposto, não pode recair sobre ele. No caso do subentendido, o locutor apresenta a sua fala como um enigma e cabe ao destinatário resolvê-lo, adquirindo total responsabilidade pelos sentidos assimilados. 
A pressuposição constitui uma das noções basilares de toda a obra de Oswald Ducrot, no entanto, desde os primeiros trabalhos do autor, ela percorreu uma longa trajetória, sofrendo uma série de reformulações. Na obra Argumentação e Linguagem, Koch (p. 55-70) apresenta uma discussão detalhada das inúmeras alterações em torno dos pressupostos e subentendidos, fundamentando-se em vários artigos de Ducrot. Inclusive, em seu próprio livro, Ducrot (1987, p. 31-43) escreve um capítulo dedicado a um reexame desses mecanismos, justificando, principalmente, o deslocamento da oposição antes estabelecida entre os dois termos.

Charaudeau e Maingueneau (2004) afirmam que as diversas propriedades dos conteúdos implícitos são objeto de grandes debates entre os linguistas, pois há problemáticas envolvendo as diversas formas de manipulação dos pressupostos e a diversidade de seu comportamento em alguns casos. Entretanto, existe um consenso, por parte dos pesquisadores, a respeito de um fator: "os pressupostos têm sempre, diferentemente dos subentendidos, um marcador no enunciado, o que lhes confere uma relativa independência em relação ao contexto" (p. 405).

\section{Sentido, Contrassentido e Argumentação}

Refletimos a respeito da Semântica Argumentativa e das informações implícitas do texto para fundamentar o entrelaçamento dos termos sentido e contrassentido em nossa base teórica. O estudo dos pressupostos e subentendidos intermediou um contato com as mensagens não explícitas do texto, proporcionando a nossa imersão em outro espaço, formado por conteúdos abstratos, que demandam uma interpretação minuciosa e mais atenta, podendo gerar diferentes significados. Sob essa perspectiva, elaboramos o roteiro a seguir, cujo posicionamento dos termos esclarece a adesão do contrassentido à nossa pesquisa:

\section{Semântica}

Semântica Argumentativa

dito e não dito

posto, pressuposto, subentendido

sentido e contrassentido

Os ditos e não ditos dos textos colaboram para a formação de diversos sentidos, variando de acordo com as intenções do enunciador. Quando são lançados aos indivíduos, esses sentidos ou ditos não provocam uma assimilação fixa e prevista, ou seja, as reações divergem conforme o contexto. Assim, se houver um objetivo específico na divulgação de determinados sentidos, o produtor do texto deve planejar os recursos linguísticos explícitos e as possíveis mensagens implícitas referentes a eles, estrategicamente, para obter os resultados desejados. Sob essa perspectiva, o movimento de implícitos nos textos é um fenômeno altamente argumentativo. A partir do momento em que mensagens são divulgadas e absorvidas de diferentes maneiras, mesmo muito bem elaboradas para certos fins, elas podem surtir efeitos agradáveis, neutros ou desconfortáveis, contrariando, muitas vezes, o próprio indivíduo ou grupos maiores, inclusive instituições ou áreas de estudo, que apresentam crenças diferentes às ideias, aos sentidos transmitidos de alguma forma.

Nessas circunstâncias, encontramos, além dos sentidos, outro fenômeno semântico implícito, o contrassentido. Trata-se de um conteúdo não linear à extensão do texto, cujo exame manifesta, de modo velado, uma ideia diferente do sentido anteriormente atrelado ao enunciado. Para Contani e Oliveira (2014, p. 113), 
"Contrassentidos são definidos como a tendência de uma palavra ou expressão, frase ou texto, ato de fala ou escuta estarem propensos a evocar reações que podem ser tanto divergentes como complementares, mas que nem sempre são cooperantes".

Para Oléron (1996), a contradição é uma realidade social e se manifesta quando as trocas entre as pessoas assumem uma forma polêmica, em que afirmação e negação se contrapõem ao mesmo conteúdo. $\mathrm{O}$ entendimento de contradição está relacionado às propriedades manifestadas por objetos, ações, pessoas e palavras. Afirmar e negar são comportamentos sociais, de posicionamento, ou de rejeição. A existência de uma mensagem dita e de outra não dita pode (ou não) suscitar o contrassentido. A partir disso, entendemos que o dito sempre será a manifestação de um sentido, independente dos resultados de suas diversas interpretações. A informação presente no contrassentido sempre será um conteúdo divergente a um sentido anterior, podendo complementá-lo.

Em um cenário de interpretações contrastantes, surge o contrassentido. Além disso, o próprio discurso publicitário, gênero de nosso interesse para essas análises, veicula outros contrassentidos, que interagem com os sentidos principais, e ambos estruturam a argumentação do texto. A propaganda, como um todo, configurase em um contrassentido, se comparada a um discurso diferente ao que ela transmite, podendo, também, apresentar outros contrassentidos em seu interior. Baseando-se na Semântica Argumentativa, nas mensagens implícitas e mais especificamente no discurso publicitário, formulamos a seguinte definição:

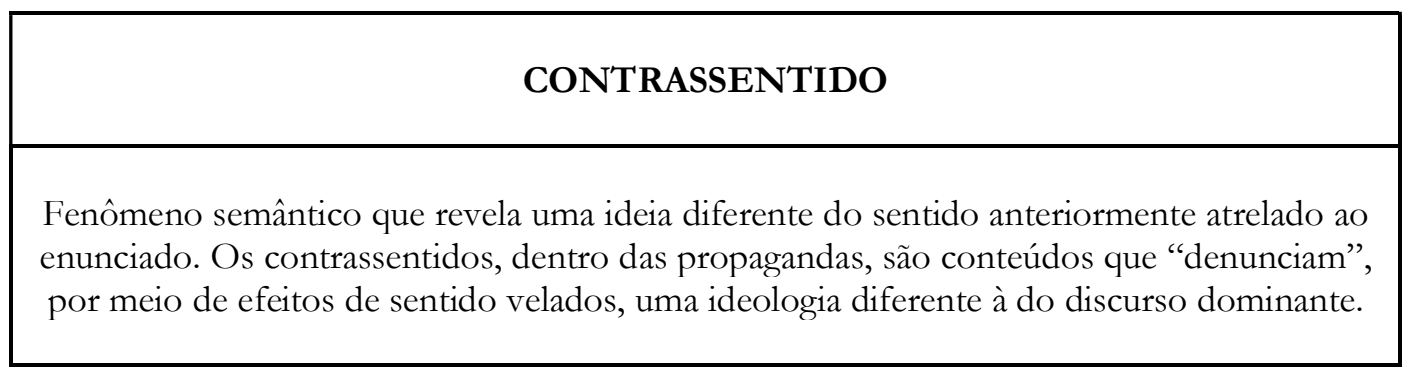

Não basta fazermos uma diferenciação entre quaisquer conteúdos que parecem se divergir e nomear a informação implícita de contrassentido; o estudo do sentido e do contrassentido demanda pesquisa e consistência. Desse modo, para reconhecermos um contrassentido, é necessário investigarmos, cuidadosamente, os princípios geradores da diferenciação entre as duas mensagens a serem analisadas, sempre considerando alguns questionamentos essenciais, como:

- Por que há um contraste?

- Como ele funciona?

- Por que sentidos diferentes estão sendo disseminados? Com quais intenções?

- Há credibilidade e confiabilidade nas grandezas que divulgam essas mensagens diferentes?

- Essas mensagens atingem o interlocutor de forma significativa?

- Socialmente, quais são as consequências da divulgação desses sentidos diferentes?

- A pesquisa sobre o contraste é relevante?

- Os movimentos implícitos, resultantes do contraste, são argumentativos?

Em nossa pesquisa, correlacionamos contrassentido e Semântica Argumentativa, pois esse recurso é proveniente do estudo dos processos implícitos e, também, funciona como uma estratégia argumentativa. Conforme a utilização das mensagens implícitas, conduzindo a sentidos e a contrassentidos, o interlocutor pode ativar conhecimentos prévios, em sua mente, e apresentar total rejeição ao que está sendo enunciado ou, 
pelo contrário, ir ao encontro das ideias propagadas. "A diferença na compreensão acerca desses domínios produz o contrassentido" (CONTANI; OLIVEIRA, 2014, p. 112). Em função disso, o uso desse recurso deve ser planejado, argumentativamente, para não apresentar falhas de comunicação e não gerar interpretações inadequadas ao objetivo pretendido pelo enunciador. Sobre essa questão argumentativa das mensagens implícitas, Fiorin afirma (2014, p. 23, grifos nossos):

Um texto diz mais do que está na superfície, pois ele não somente transmite conteúdos explícitos, mas também conteúdos implícitos, marcados no enunciado ou na situação de comunicação, que apreendemos ao fazer inferências. Os conteúdos implícitos podem ser pressupostos e subentendidos. O conteúdo explícito será denominado 'posto', enquanto o conteúdo implícito desencadeado pela formulação do enunciado, independentemente da situação de enunciação, será cognominado 'pressuposto'. [...] O uso da pressuposição é um forte recurso argumentativo, uma vez que ele conduz a aceitar certas ideias do enunciador.

Transportando os sentidos e os contrassentidos ao universo do discurso publicitário, a criação argumentativa das mensagens implícitas deve ser elaborada, meticulosamente, para não amenizar, no leitor/ consumidor, a necessidade, o desejo de comprar o produto anunciado. Por exemplo, em propagandas que divulgam cosméticos rejuvenescedores e instauram a ideia de ocultação da velhice, os sentidos emanados pelo texto e imagem do anúncio precisam seguir essa ideologia e criticar o envelhecimento, enaltecendo a beleza e as vantagens da juventude, apresentando-a como meta a ser perseguida.

Se esse discurso deixar transparecer, implicitamente, algum indício de ganhos e vantagens na velhice, o leitor/consumidor pode interromper o seu processo mental sobre as "maravilhas da juventude" e, analisando melhor a situação, diminuir o seu entusiasmo pelo cosmético. Assim, não haveria motivos consistentes para a compra do produto, devido a falhas persuasivas do funcionamento de implícitos. Nessas propagandas, o contrassentido proveniente da ciência da velhice, a Gerontologia, aceitar a velhice, deve manter-se velado, e o publicitário deve atentar-se para o fato de nenhuma marca, linguística ou não, direcionar o pensamento do seu público a outra ideologia.

No entanto, verificamos que os contrassentidos, nesse tipo de peça, são fundamentais para conferir veracidade à propaganda. Desse modo, eles são mais ocultos, e os leitores nem sempre captam determinadas nuances intencionais da linguagem argumentativa. Por isso, os contrassentidos são recursos argumentativos implícitos. A sua posição no texto, seus efeitos de sentido e seu grau de disfarce configuram-se em estratégia e, como resultado, o publicitário acaba valorizando apenas a ideologia de ocultação da idade, favorável ao cosmético rejuvenescedor anunciado.

O discurso publicitário constrói o seu anúncio com base em "verdades" que sustentam a necessidade de adquirir um produto. A ideia de juventude, relacionada à felicidade, é veiculada como uma verdade incontestável e os argumentos seguintes são elaborados a fim de realçar a jovialidade e denegrir o envelhecimento. O anúncio não oferece oportunidade ao leitor/consumidor de apresentar outros ideais, ele não permite avaliações diferentes, simplesmente impõe a sua ideologia, consolidando uma crença imutável. Para Guimarães (2009, p. 62), "funcionando de maneira lógica, o pressuposto torna-se difícil de ser recusado, devendo ser aceito pelo locutor bem como pelo interlocutor". Com base nessa mesma consideração, Koch (1984, p. 59) afirma que "o valor argumentativo de um enunciado seria, pois, uma espécie de obrigação relativa à maneira pela qual o discurso deve ser continuado". E, para Ducrot (1987, p. 30),

[A pressuposição] possibilita aprisionar o ouvinte em um universo intelectual que ele não escolheu, mas que lhe é apresentado como coextensivo ao próprio diálogo. Esse universo não pode mais ser negado nem questionado sem que o referido diálogo seja rejeitado em sua totalidade. Agora, se o pressuposto, diferentemente do subentendido, não é um fato de retórica ligado à enunciação, mas inscreve-se na própria língua, é preciso concluir que a língua, independentemente das utilizações que dela podem ser feitas, apresenta-se, fundamentalmente, como o lugar do debate e da confrontação das subjetividades. 
Desse modo, se as propagandas defenderem a ocultação da idade e o leitor/consumidor aceitar a sua idade, não há uma troca, e a comunicação não tem sentido. Por isso, o anúncio enaltece, da forma mais argumentativa possível, os atributos da juventude, para a propaganda configurar-se na aquisição do produto. O cosmético apenas será vendido se o leitor/consumidor encontrar razões significativas para a sua compra. Com base em Contani e Oliveira (2014, p. 109), “o que faz sentido para uns é contraditório para outros, criando, assim, a alternância entre sentidos e contrassentidos". Diante desse tipo de anúncio, alguns leitores idosos, em momentos de conflito com a sua idade cronológica, escassos de informações provenientes de outros discursos, como o gerontológico, aceitam os valores "ensinados" pelas propagandas de cosméticos rejuvenescedores e tornam-se consumidores fiéis desse tipo de cosmético. A publicidade aproveita-se das fraquezas e da falta de conhecimento dos indivíduos para potencializar os milagres de seus produtos.

Segundo Maingueneau (2001, p. 20), "todo ato de enunciação é fundamentalmente assimétrico: a pessoa que interpreta o enunciado reconstrói seu sentido a partir de indicações presentes no enunciado produzido, mas nada garante que o que ela reconstrói coincida com as representações do enunciador". Assim, para assimilarmos um enunciado, devemos mobilizar saberes muito diversos, priorizando um dado instável, o contexto. No discurso publicitário, essa instabilidade do contexto não atua de modo favorável, pois o enunciador deseja manter um único cenário, favorável ao produto. Então, com o intuito de disseminar mensagens selecionadas, o anúncio trabalha, persuasivamente, com os conteúdos implícitos. Se a argumentação for eficaz, o contexto será extraído do próprio anúncio, e não do indivíduo; por consequência, o leitor/consumidor assume o enunciado como verdadeiro. Para Maingueneau (p. 20),

fora de contexto, não podemos falar realmente de sentido de um enunciado, mas, na melhor das hipóteses, de coerções para que um sentido seja atribuído à seqüência verbal proferida em uma situação particular, para que esta se torne um verdadeiro enunciado, assumido em um lugar e em um momento específicos, por um sujeito que se dirige, numa determinada perspectiva, a um ou a vários sujeitos.

Sobre argumentação e implícitos, conforme Guimarães (2009), a interligação da semântica com a pragmática manifesta-se não só na superfície do texto como também nos seus implícitos, sob a forma de pressupostos ou de subentendidos que, na comunicação, representam-se como estratégias linguísticas e referenciais, fazendo compreender também os silêncios (sem grifos no original). Assim, "Não se nega o fato da presença do implícito em tudo o que dizemos; cada vez que falamos, oculta-se em nossa fala grande parte de implícito - a linguagem comportando uma parte de significação deixada à interpretação" (p. 61). Desse modo, há sempre incertezas sobre a essência comunicacional, ou seja, sentidos e contrassentidos embaralham a nitidez do conteúdo das mensagens.

De acordo com Contani e Oliveira (2014), os personagens da enunciação se valem de determinadas estratégias, como o implícito e o explícito, para estabelecer o sentido global do texto, cujo respaldo liga-se a três níveis indissociáveis: o pragmático, o semântico e o sintático. Desse modo, a Semântica Argumentativa, considerada uma ramificação as Pragmática, examina a relação entre locutor e alocutário, em determinada situação discursiva, orientando os efeitos de sentido das mensagens por meio de diversos procedimentos argumentativos. As palavras são dirigidas ao destinatário com certos valores, inerentes à situação comunicativa, contribuindo para a compreensão final do que foi dito. Esses elementos indispensáveis aos efeitos persuasivos dos enunciados são chamados de marcas linguísticas da enunciação ou da argumentação.

A respeito do uso de implícitos argumentativos, Maingueneau (1996) explica:

Dependendo se são colocados em um ou em outro nível, os conteúdos não recebem absolutamente o mesmo estatuto interpretativo. Se os postos são apresentados como aquilo ao que se refere a enunciação e portanto submetidos a uma contestação eventual, os pressupostos lembram de maneira lateral elementos cuja existência é apresentada como óbvia. Essa dissimetria é capital; permite focalizar a atenção sobre o posto e "fazer passar" 
discretamente o pressuposto. Decerto, os pressupostos não são necessariamente utilizados para finalidades manipuladoras, mas é inegável que oferecem essa possibilidade (p. 95, grifos nossos).

Cabral (2011) afirma que o uso dos implícitos sempre cumpre uma função nas interações verbais e, muitas vezes, são dotados de força argumentativa, "sejam subentendidos, sejam pressupostos, eles têm um papel discursivo inegável” (p. 62). Também, comprovando o emprego argumentativo dos implícitos, Koch (1984, p. 70) ressalta que "o uso retórico da pressuposição [...] é um recurso retórico de segundo nível, ou seja, faz parte da retórica ou pragmática aplicada, constituindo-se em uma manobra argumentativa de grande eficácia”. Desse modo, há intencionalidade ao selecionar determinadas mensagens implícitas na produção de textos. Em toda comunicação, subjaz uma carga de sentido que manifesta a intencionalidade e a ideologia de seu autor, as quais podem ser reveladas, de forma progressiva, por meio de pistas sinalizadas pelos conteúdos implícitos, por exemplo.

\section{Considerações FinaIs}

Entrelaçamos o contrassentido à nossa fundamentação teórica, com base nos ensinamentos da Semântica Argumentativa, no dito e não dito, no posto, pressuposto e subentendido, nos sentidos e contrassentidos. Desse modo, concluímos que o contrassentido é um fenômeno semântico-argumentativo, atua como estratégia linguística, transmite efeitos de sentido e pode ser considerado uma informação implícita, já que aparece de forma mais velada na linguagem persuasiva de um tipo específico de anúncio.

Em nosso estudo, o caráter ideológico entre a Gerontologia e a publicidade permitiu distinguir o sentido e o contrassentido, que não é fonte exclusiva para essa formação, pois o campo de pesquisa dos sentidos e contrassentidos é muito vasto. Salientamos que, caso o leitor/consumidor não se motive com um anúncio publicitário de cosméticos rejuvenescedores, isso não significa a ausência de sentidos do texto, mas os sentidos serão configurados em outra ideologia, mais conivente com o contexto do indivíduo.

Conceitos incompatíveis podem existir e são resultados de escolhas e decisões. Segundo Oléron (1996), as realidades de nosso ambiente social são o produto de categorizações e julgamentos feitos sobre os dados percebidos. Muitos são os acontecimentos que não se prestam a uma divisão totalmente dicotômica, porque se situam no contínuo, na transição. Por exemplo, um círculo quadrado é uma figura que ilustra essa incompatibilidade, pois, se executada desajeitadamente por uma criança, pode integrar ambas as figuras geométricas. Estes não são jogos mentais simples, e as disciplinas científicas não estão imunes a esse tipo de consideração, ou seja, a esse jogo de incompatibilidades.

Nunca haverá falta de sentidos, mesmo que eles sejam contrários à ideia transmitida inicialmente. Haverá trocas de ideologias entre diversos objetos de estudo, entretanto não compete a nós determinar a postura ideológica "verdadeira" e "mais correta". Cada área constrói a sua ideologia de acordo com seus objetivos, e os componentes psicológicos e sociais do indivíduo terão o seu peso ao entrar em contato com determinados valores. Para Oléron (1996), não há vida sem ambivalência, sem coexistência de amor e ódio, medo e atração, aproximação e afastamento. A vida psicológica e a social são marcadas por conflitos, que existem entre grupos, dentro dos indivíduos, pois, de acordo com o autor,

Les intérêts et les déterminants qui conduisent à agir sont antagonistes chez l'escroc et as victime, les combattants de cahque côté de la ligne de feu, les hommes politiques em compétition pour la conduite de l'Etat. Combien de nous n'aspirent-ils pas à la fois à gagner plus d'argente et à travailler moins, vivre des aventures originales et à bénéficier de la sécurité, à profiter des personnes et des choses sans em payer de prix? On dirá facilemente que ces intérêts et ces aspirations sont contradictoires et cependant leur coexistence est difficilement niable (OLÉRON, 1996, p. 57-58). 
Desse modo, reafirmamos a ideia de que há alternância e complementaridade entre sentidos e contrassentidos. Posturas, mesmo divergentes, interagem e complementam-se, pois dialogam e são responsáveis pela arquitetura argumentativa do texto. Além disso, "É preciso aceitar também que o contrassentido recebe sua carga no diálogo e no domínio dos códigos oral e escrito, os dois localizados no âmbito do conhecimento da língua" (CONTANI; OLIVEIRA, 2014, p. 118). Por fim, reforçamos a inserção do contrassentido na Semântica Argumentativa, mobilizando as contribuições que a Teoria da Argumentação na Língua e seus desdobramentos podem oferecer para a leitura e a escrita, procurando sensibilizar o leitor a explorar as estratégias linguísticas representadas pelas informações implícitas.

\section{REFERÊNCIAS}

ANSCOMBRE, J.-C.; DUCROT, O. L'argumentation dans la langue. Langages, 10e a., n. 42, p. 5-27, 1976. Disponível em: http://bit.ly/3qyKfBf.

AMOSSY, R. A argumentação no discurso. Trad. de Angela M. S. Corrêa et al. São Paulo: Contexto, 2018.

BARBISAN, L. B. Semântica argumentativa. In: FERRAREZI JUNIOR, C.; BASSO, R. (org.). Semântica, semânticas: uma introdução. São Paulo: Contexto, 2013. p. 20-30.

CABRAL, A. L. T. A força das palavras: dizer e argumentar. São Paulo: Contexto, 2011.

CHARAUDEAU, P.; MAINGUENEAU, D. Dicionário de análise do discurso. Tradução Fabiana Komesu (coord.). São Paulo: Contexto, 2004.

CONTANI, M. L.; OLIVEIRA, E. G. de. Sentidos e contrassentidos nas organizações. In: MARCHIORI, M. (org.). Linguagem e discurso. São Caetano do Sul: Difusão; Rio de Janeiro: Senac Rio de Janeiro, 2014. p. $109-120$.

DUCROT, O. Princípios de semântica lingüistica: dizer e não dizer. Tradução Carlos Vogt e Rodolfo Ilari. São Paulo: Cultrix, 1977.

DUCROT, O. O dizerer e o dito. Campinas: Pontes, 1987. (Revisão técnica da tradução de Eduardo Guimarães).

FERRAREZI JUNIOR, C. Semântica para a educação básica. São Paulo: Parábola, 2008.

FIORIN, J. L. O desafio é ler as entrelinhas: cresce na vida contemporânea o uso argumentativo de inferências, pressupostos e subentendidos. Revista Lingua, p. 22-25, jan. 2014.

GUIMARÃES, E. Figuras de retórica e argumentação. In: MOSCA, L. do L. S. (org.). Retóricas de ontem e de hoje. São Paulo: EDUSP, 1997. p. 145-160.

GUIMARÃES, E. Texto, discurso e ensino. São Paulo: Contexto, 2009.

ILARI, R. Introdução à semântica: brincando com a gramática. São Paulo: Contexto, 2001.

KOCH, I. G. V. Argumentação e linguagem. São Paulo: Cortez, 1984. 
MAINGUENEAU, D. Pragmática para o discurso literário. Tradução Marina Appenzeller. São Paulo: Martins Fontes, 1996.

MAINGUENEAU, D. Análise de textos de comunicação. Tradução Cecília P. de Souza-e-Silva e Décio Rocha. São Paulo: Cortez, 2001.

OLÉRON, P. L'argumentation. 4. ed. Paris: Presses Universitaires de France, 1996.

OLIVEIRA, E. G. de. Operadores argumentativos e marcadores discursivos na língua falada. 1999. Tese (Doutorado em Linguística) - Universidade de São Paulo, São Paulo, 1999.

OLIVEIRA, E. G. de. Argumentação: da Idade Média ao século XX. Signum: Estudos da Linguagem, Londrina, v. 7, n. 2, p. 109-131, dez. 2004. Disponível em: http://bit.ly/3aAro3g. 